\title{
An update for UK podiatrists performing toenail surgery on patients who are taking antithrombotic medications: it's about bleeding time
}

Ian N Reilly ${ }^{1,2}$. BSc, MSc, FCPodS, FFPM RCPS(Glasg). Consultant Podiatric Surgeon

Toby Blandford ${ }^{3}$. BSc(Hons). Private Practitioner

\begin{abstract}
Nail surgery for the permanent removal of all or part of the nail unit can be performed via incisional or physically ablative techniques for conditions such as ingrown, mycotic, or dystrophic toenails. In the United Kingdom podiatric community, where phenol techniques are the standard of care for ablation of the matrix, there remains confusion about the management of patients undergoing nail surgery who are concurrently taking antithrombotic medication(s). The aim of this paper was to review the literature describing treatment strategies for antithrombosed patients undergoing nail surgery. However, having found limited evidence, the authors considered relevant and associated literature in the field of cutaneous/dermatological surgery and extrapolated those findings for patients undergoing nail avulsion surgery. A case-by-case risk assessment is warranted in all patients but as a general rule, the podiatrist can perform nail surgery without the patient ceasing their antithrombotic medication.
\end{abstract}

Keywords: nail surgery, antithrombotics, anticoagulation, antiplatelet, bleeding.

Level of clinical evidence: 5 (expert review).

Date: May 2021. Preprint. For later submission to a UK podiatry journal.

\section{Index}

Introduction 1

Method

Results 4

Discussion

Conclusion

Author information

Declaration 8

References

\section{Introduction}

Nail pathology

There are many disorders of the nail unit that may benefit from a surgical approach. The ingrown toenail (IGTN) is one of the most commonly seen and disabling foot problems encountered in the general population. The condition occurs when the nail plate punctures the sulcus, giving rise to pain and inflammation". The presentation of an IGTN was divided into three stages by Heifetz in $1937^{3}$ and can be summarised as:

- stage one: some inflammation, swelling, and pain, 
- stage two: more inflammation, pain and granulation tissue,

- stage three: abscess formation and chronic induration of the nail fold.

Stage two and three presentations typically require a surgical solution. Mycotic and dystrophic toenails may also benefit from permanent ablation ${ }^{4,5}$. Laco ${ }^{6}$ classifies nail surgery techniques into two divisions:

- Excision of the pathological nail and/or soft tissue using sharp instrumentation, e.g., the Fowler procedure

- Destruction of the pathological tissue by physical means such as topical chemotherapy, e.g., use of phenol.

Eekhof et $\mathrm{al}^{2}$ state that surgical interventions are more effective than non-surgical interventions in preventing the recurrence of an ingrowing toenail if conservative care fails or is not appropriate. Nail surgery procedures are carried out by podiatrists, podiatric surgeons, general practitioners (GPs), extended scope nurse practitioners, dermatologists, general surgeons, and orthopaedic surgeons, though techniques and outcomes may vary ${ }^{8,9}$. The most regularly performed technique is the phenolalcohol procedure ${ }^{2,1,11}$ (see Fig. 1). There are numerous incisional surgical techniques for ablation of the peri-ungual tissue and nail plate (partial or total resection). The index procedures are the (modified) Winograd procedure ${ }^{12}$ and the Zadik procedure ${ }^{13}$ for partial and total avulsion techniques respectively. In skilled hands these may be the best option for a small cohort of patients (see Fig. 2).

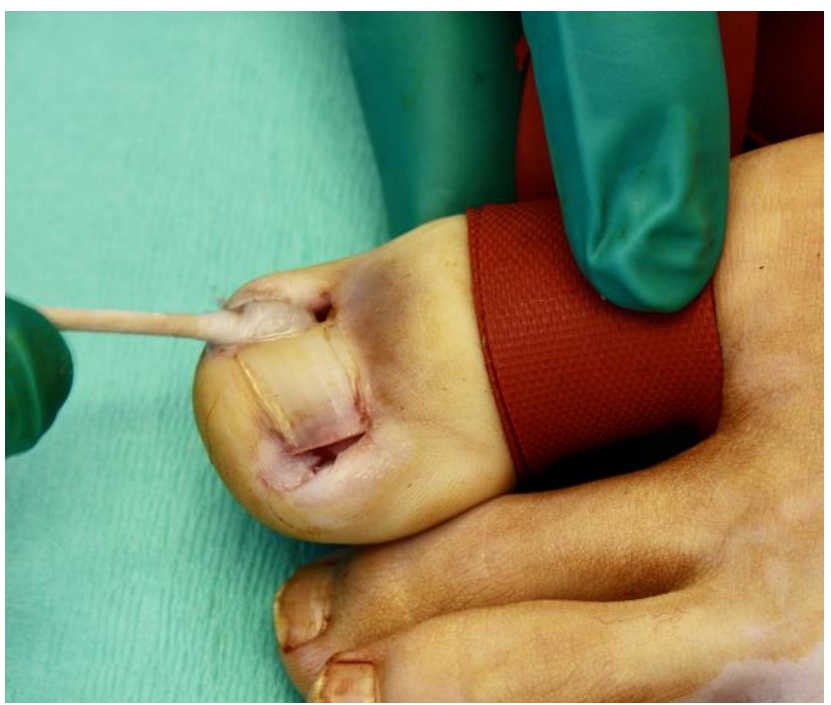

Figure 1: phenolic partial nail avulsion

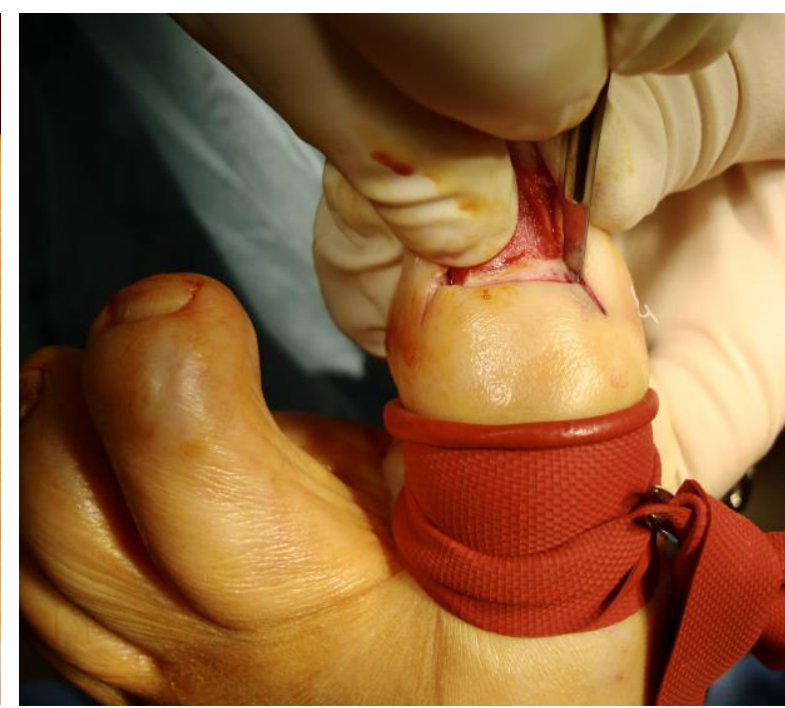

Figure 2: incisional total nail avulsion

In the United Kingdom (UK) podiatric community there is confusion concerning the management of patients undergoing nail surgery who are concurrently taking antithrombotic medication, evidenced by those at the forefront of teaching nail surgery to under- and post-graduate podiatrists $^{14}$. Considering that a cohort of the profession believes that podiatry is a branch of 'medicine' rather than 'healthcare', and that podiatrists should be the go-to profession for most foot pathology, any hesitancy in taking full responsibility for the management of this subset of patients seems contrary to that ambition. The paucity of available published literature in this field often lacks an evidenced-based argument. For example, the (generally excellent) Northern Care Alliance NHS Group nail surgery guidance document considers that nail surgery patients taking anticoagulants are at 'increased risk' and, following communication with the appropriate consultant/anticoagulation nurse, should come under the care of Band 6/7 (rather than Band 5) clinician ${ }^{15}$. The aim of this article is therefore to review the available evidence for patients undergoing nail surgery that are on 
concurrent antithrombotic therapy, and to suggest treatment strategies for podiatrists in the UK to best manage their patients.

\section{Antithrombotics}

Disruption of atherosclerotic plaques in arteries triggers platelet aggregation and activation of coagulation pathways, which culminates in the formation of platelet-rich atherothrombosis. This process is the underlying cause of myocardial infarction (MI), ischaemic stroke, and acute limb ischaemia. The blood flow in veins is slower than that in arteries and therefore venous thrombi contain fewer platelets (and more fibrin) than arterial thrombi. Thrombosis in veins leads to deep vein thrombosis and pulmonary embolism (DVT/PE), collectively known as venous thromboembolism (VTE). With the preponderance of platelets in arterial thrombi, antiplatelet therapy is the cornerstone for prevention and treatment of atherothrombosis; anticoagulant therapy is the mainstay for the prevention and treatment of $\mathrm{VTE}^{16}$. The main antithrombotics (with a brief drug overview) are listed at table 1. It is assumed that the reader is familiar with coagulation physiology and therefore a precis of the pathways is outside the scope of this document.

\begin{tabular}{|c|c|c|c|}
\hline Drug & Indication & Mode of action & Monitoring \\
\hline \multicolumn{4}{|l|}{ Antiplatelet } \\
\hline Aspirin & Secondary prevention after ACS/CVA. Pain relief. & $\begin{array}{l}\text { Irreversible COX-1 } \\
\text { inhibitor }\end{array}$ & $\begin{array}{l}\text { Platelet function } \\
\text { assay; serum drug } \\
\text { levels }\end{array}$ \\
\hline Clopidogrel & $\begin{array}{l}\text { ACS (reduce risk of death); secondary prevention of } \\
\text { CVA, MI, and vascular death in patients with recent } \\
\text { MI, CVA or PAD. }\end{array}$ & $\begin{array}{l}\text { P2Y12 ADP receptor } \\
\text { antagonist }\end{array}$ & $\begin{array}{l}\text { Platelet function } \\
\text { assay }\end{array}$ \\
\hline Ticagulor & $\begin{array}{l}\text { Reduce thrombotic cardiovascular events in patients } \\
\text { with ACS, including stent thrombosis. }\end{array}$ & P2Y12 receptor inhibitor & $\begin{array}{l}\text { Platelet function } \\
\text { assay }\end{array}$ \\
\hline Prasugrel & $\begin{array}{l}\text { Reduce thrombotic cardiovascular events in patients } \\
\text { with ACS including stent thrombosis. }\end{array}$ & $\begin{array}{l}\text { P2Y12 ADP receptor } \\
\text { inhibitor }\end{array}$ & $\begin{array}{l}\text { Platelet function } \\
\text { assay }\end{array}$ \\
\hline Dipyridamole & Reduce risk of stroke in patients with TIA/CVA. & PDE $3 / 5$ inhibitor & None \\
\hline \multicolumn{4}{|l|}{ Anticoagulant } \\
\hline Warfarin & $\begin{array}{l}\text { Prophylaxis and treatment of DVT and PE, and of } \\
\text { VTE complications with AF and cardiac valve } \\
\text { replacement; risk reduction for embolic events after } \\
\text { MI. }\end{array}$ & $\begin{array}{l}\text { Vitamin K epoxide } \\
\text { reductase inhibitor. May } \\
\text { induce hypercoagulable } \\
\text { state. }\end{array}$ & INR \\
\hline $\begin{array}{l}\text { Heparin } \\
\text { (Unfractionated) }\end{array}$ & $\begin{array}{l}\text { Prophylaxis and treatment of DVT and PE, and of } \\
\text { VTE complications with AF }\end{array}$ & Antithrombin III & $\begin{array}{l}\text { activated partial } \\
\text { thromboplastin time }\end{array}$ \\
\hline $\begin{array}{l}\text { Heparin } \\
\text { (fractionated) }\end{array}$ & Prophylaxis and treatment of DVT and PE & Antithrombin III & Anti-factor Xa \\
\hline Dabigatran & $\begin{array}{l}\text { Reduce the risk of CVA and VTE in patients with } \\
\text { nonvalvular AF. }\end{array}$ & Direct thrombin inhibitor & $\begin{array}{l}\text { Thrombin or ecarin } \\
\text { clotting time. }\end{array}$ \\
\hline Apixaban & $\begin{array}{l}\text { Reduce the risk of CVA and VTE in patients with } \\
\text { nonvalvular AF. }\end{array}$ & Factor Xa inhibitor & Prothrombin time \\
\hline Edoxorban & $\begin{array}{l}\text { Reduce the risk of CVA and VTE in patients with } \\
\text { nonvalvular AF. }\end{array}$ & Factor Xa inhibitor & Prothrombin time \\
\hline Rivaroxaban & $\begin{array}{l}\text { Reduce the risk of CVA and VTE in patients with } \\
\text { nonvalvular AF; treatment of DVT/PE; prophylaxis of } \\
\text { DVT after hip or knee replacement. }\end{array}$ & Factor Xa inhibitor & Prothrombin time \\
\hline
\end{tabular}

Table 1: main antithrombotic drugs, adapted from Brown et al

(abbr: ACS - acute coronary syndrome; ADP - adenosine diphosphate; AF - atrial fibrillation; COX - cyclo-oxygenase; CVA cerebrovascular accident; INR - international normalized ratio; PAD - peripheral arterial disease; PDE - phosphodiesterase)

For the patient on antithrombotic medication, the risk comes down to the following dichotomy: cease the medication and risk the formation of a thrombosis; or continue the medication and run the risk of a complication from bleeding ${ }^{18,19}$. Should continuation of pharmacotherapy be the strategy, the practitioner must minimise and manage the haemorrhagic risk ${ }^{20}$ (see Fig. 3, modest post- 
procedure strikethrough). Use of a thicker, more absorbent, alginate-based, or compressive dressing may help with excessive bleeding ${ }^{21,22}$, always being aware of the dangers of compression in a digit (see Fig. 4). Fig. 5 demonstrates a haematoma that developed in the apex of the hallux after an incisional nail technique performed by the senior author (but with no long term sequalae seen).

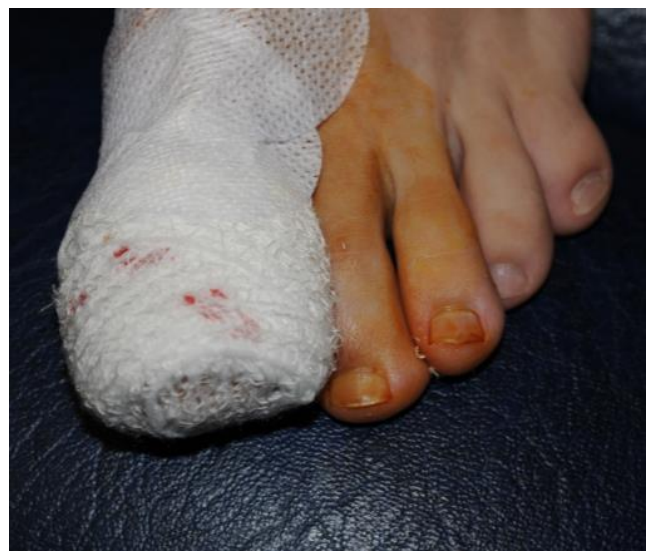

Figure 3: minor post-procedure bleed

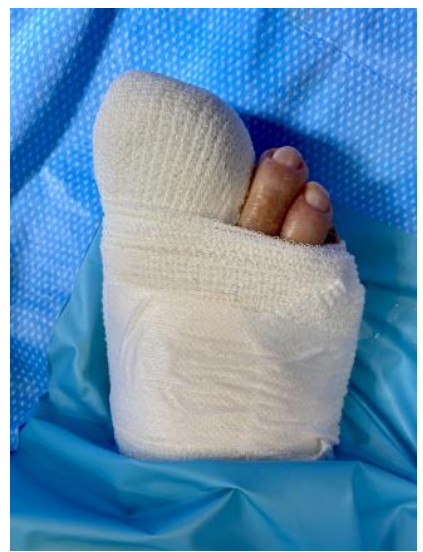

Figure 4: thick(er) dressing

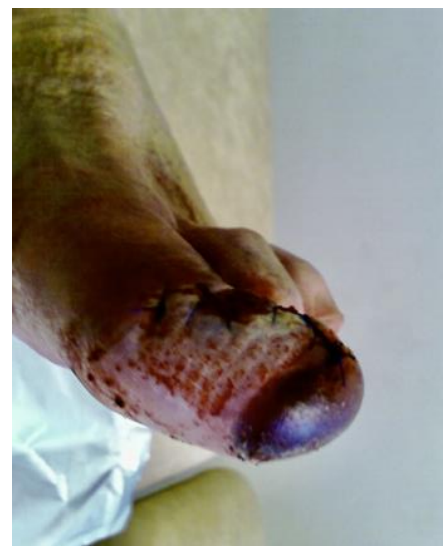

Figure 5: haematoma

\section{Method}

An initial Google Scholar literature search suggested that little had been written regarding nail surgery on the antithrombosed patient. Nonetheless, the authors performed a literature search that involved identifying research evidence from the following sources:

- Electronic databases

- Reference lists

Search strategy

- Step 1: The following databases were searched via the NHS Healthcare Advanced Database Search (HDAS) search engines AMED, CINAHL, EMBASE, and Medline,

- Step 2: examining the reference lists of all identified sources.

The following Boolean and free text keywords were used:

"((nail).ti,ab OR (onychocryptosis).ti,ab) AND ((anticoag $\left.{ }^{*}\right) . t i, a b$ OR (antithrombo*).ti,ab OR (antiplatelet).ti,ab)".

Evidence was sought on cutaneous/dermatological surgery for the antithrombosed patient: this was searched using Google Scholar free text keywords and via reference lists.

\section{Results}

0, 11, 12 and 20 papers were found from the four database searches respectively, as per the search strategy, none of which were relevant to the aim of this paper. Two specifically relevant papers were found via the initial Google Scholar search on nail surgery (see summary at table 2). One of these $\mathrm{e}^{23}$ is 12 years old and primarily concerns the use of warfarin and can therefore be considered at least partially out of date as warfarin has largely been replaced by newer drugs. It is, however, the most useful document in this field the authors could find. The second is from the (now Royal) College of Podiatry Nail Surgery guideline ${ }^{24}$.

Many papers in the field of cutaneous/dermatological surgery were identified (e.g., see table 3) with further papers from the dental profession considered where relevant. 


\begin{tabular}{|c|c|}
\hline $\begin{array}{l}\text { Dept., } \\
2009\end{array}$ & $\begin{array}{l}\left.\text { Persantin Retard } ®) \text {, aspirin plus dipyridamole (Asasantin Retard }{ }^{\circledR}\right) \text {. The use of anti-platelet agents can be safely } \\
\text { ignored unless in combination with oral anticoagulants when the bleeding level will increase a little further. } \\
\text { There are other oral anticoagulants (rivaroxaban or dabigatran) in use that are not monitored by INR testing as they } \\
\text { are not vitamin K antagonists. Podiatrists will increasingly need to ask about such medicines - especially if a patient } \\
\text { has had recent orthopaedic surgery. } \\
\text { Summary: } \\
\text { - Bleeding complications, while inconvenient, do not carry the same risks as thromboembolic complications. } \\
\text { - Patients whose INR results are within the acceptable therapeutic range are more at risk of permanent disability } \\
\text { or death if they have their warfarin stopped prior to a surgical procedure than if they continue it. } \\
\text { - Published reviews of the available literature advise that oral anticoagulants should not be stopped prior to minor } \\
\text { surgical procedures. }\end{array}$ \\
\hline $\begin{array}{l}\text { Gohil, } \\
2019\end{array}$ & $\begin{array}{l}\text { The use of anticoagulants should not prevent nail surgery, assuming the patient is suitable in all other respects, } \\
\text { although the patient should be alerted that post-operative bleeding may be prolonged and their advised aftercare } \\
\text { regime modified to reflect this. Recorded INR (International Normalised Ratio- a measure of the clotting time) values } \\
\text { vary in accordance with the patient's individual condition and the higher the INR value, the longer the blood will take } \\
\text { to form a clot; in many anti-coagulated cases the INR is maintained by warfarin therapy between } 2-3 \text {, meaning that } \\
\text { the clotting process will take approximately } 2-3 \text { times as long as normal (i.e., approximately } 10-15 \text { mins, rather than } \\
\text { the normal } 5 \text { minutes). Stopping the use of anticoagulant medication or avoiding surgery is not usually justified in } \\
\text { these patients. } \\
\text { It is advisable to review manufacturers' recommendations prior to undertaking any procedure with the new range of } \\
\text { new anticoagulants (NOACs). Patients taking these medications are not monitored by INR recording so clinicians } \\
\text { should consider seeking the opinion of their anticoagulant team prior to undertaking a nail surgical procedure. } \\
\text { Whereas the effects of warfarin can be reversed quickly with vitamin K injection, reversal of the anticoagulant effects } \\
\text { of NOACs is likely to require specialist advice. }\end{array}$ \\
\hline
\end{tabular}

Table 2: summaries $\mathrm{UK}$ podiatric references ${ }^{23,24}$

\begin{tabular}{|c|c|}
\hline Agent & Guideline management \\
\hline Aspirin monotherapy & No increased incidence of bleeding complications. Safe to continue. \\
\hline Clopidogrel monotherapy & $\begin{array}{l}\text { Conflicting evidence. Probable small increase in bleeding complications. Benefits of continuation } \\
\text { likely outweigh risks. }\end{array}$ \\
\hline Warfarin monotherapy & $\begin{array}{l}\text { Conflicting evidence. Probable small increase in bleeding complications. Benefits of continuation } \\
\text { likely outweigh risks provided INR is in range (conservative INR cut off }<3 \text { suggested, unless } \\
\text { higher therapeutic range indicated - e.g., recurrent venous thromboembolism on } \\
\text { anticoagulation). }\end{array}$ \\
\hline $\begin{array}{l}\text { Direct oral anticoagulant } \\
\text { (DOAC) monotherapy }\end{array}$ & Insufficient evidence for recommendation. Further research needed. \\
\hline Multiple agent regimens & $\begin{array}{l}\text { Probable increase in bleeding complications. AC/AP monotherapy preferable, but seek specialist } \\
\text { advice before adjusting regimens due to high-risk cohorts }\end{array}$ \\
\hline
\end{tabular}

Table 3: adapted from Isted et al, $2017^{25}$ : summary of recommendations for minor cutaneous surgery

\section{Discussion}

Intra-operative bleeding is not a concern (save for effective use of a digital tourniquet as a prerequisite to allow phenol the time to destroy the matrix); author experience and the literature suggest that post-operative bleeding is highly unlikely to cause any long term sequalae in a nail surgery patient.

Richert ${ }^{22}$ posits: "As nail surgery is mainly performed with a tourniquet, the risk of perioperative bleeding is minimal. Bleeding may occur postoperatively when the tourniquet is removed. Compressive dressing for half an hour with the limb elevated will suffice in most instances. The dressing should be changed afterward and the wound checked. If bleeding persists, it may be dramatically lessened by the injection of a load of fluid (i.e., $0.5 \mathrm{~mL}$ of bupivacaine) on the lateral aspect of the digit/toe that will press onto the digital proper artery". Other authors concur with thicker bandaging ${ }^{23,26}$.

The use of adrenaline-containing local anaesthetic for digital anaesthesia has long been verboten in UK podiatry and always taught as such. Its use for this group of patients is worthy of a separate paper but the complication of digital necrosis has long been refuted as a real concern ${ }^{27,28}$. While the authors of this paper do not advocate the routine use of adrenaline-containing local anaesthetic for every digital anaesthesic, its use in antithrombosed patients could be considered, if only for the management prolonged of post-procedure bleeding. 
Beyond the limited nail-specific literature, the field of cutaneous/dermatological surgery was replete with evidence. Various authors have concluded that the evidence increasingly favours continuation of antithrombotic medications during such surgery because the risks associated with stopping these medications exceeds the benefits ${ }^{21,2,29-33}$, and that the surgical results of antithrombosed patients compared to control groups are identical ${ }^{25,29}$.

Blasdale and Lawrence ${ }^{34}$ performed a prospective controlled observational study of 65 warfarinised patients undergoing excision of cutaneous tumours (mean peri-operative INR: 2.1, range 1.0 - 4.2) compared to 92 non-warfarinised in a control group. They found no increase in intra-operative bleeding tendency in the warfarinised patients but five of those patients (8\%) reported moderate or severe post-operative bleeding, compared to no significant post-operative bleeding reported in the control group. The authors concluded that even when INR is in the therapeutic range, the risk of post-operative bleeding is increased for warfarinised patients: a reminder for all not to put our entire faith in the result of a single laboratory test.

Bordeaux et $\mathrm{al}^{29}$ considered the rates of bleeding, infection, flap/graft necrosis and dehiscence in dermatological surgery, and examined this data in relationship to the type/anatomical location of the repair, antibiotic use, antiplatelet or anticoagulant use. They found that patients on both clopidogrel and warfarin were 40 times more likely to have bleeding complications. A range of complications was demonstrated in their study, but all resolved without sequelae, suggesting that the incidence of complications in dermatological surgery is low, even when multiple oral anticoagulant and antiplatelet medications are continued. The authors concluded that anticoagulant and antiplatelet medications should be continued to avoid adverse thrombotic events.

Callahan et $\mathrm{al}^{32}$ reviewed the literature on antithrombotic medications commercially available in the United States in dermatological surgery. The authors found concerns regarding bleeding, but no reports of life-threatening haemorrhage from continued antithrombotic therapy. They note that potentially fatal cardiovascular events after cessation of antithrombotic medications are increasingly recognised, leading to the growing acceptance in dermatology that the risk of stopping most antithrombotics may outweigh the risks of bleeding incurred by continuing antithrombotic therapy.

The British Society for Dermatological Surgery (BSDS) issued guidance on antithrombotics and skin surgery in $2016^{30}$ to complement generic local hospital protocols that mainly relate to more major surgery, noting that those protocols typically address procedures with a much larger risk of bleeding than skin surgery. They also state that what constitutes as 'minor' skin surgery is often not clearly defined, and suggest a stratification of bleeding risk by procedure type (from highest to lowest):

- Secondary intention wounds following excision,

- Local flaps,

- Grafts,

- Direct closure,

- Curettage and electrocautery.

The BSDS document algorithm suggests that one can proceed with surgery for all minor to moderate procedures for those patients with an INR of less than 3.5. This can be usefully extrapolated to conclude that nail surgery - even for incisional techniques - should also be regarded as low risk, based on how the BDSD guideline stratify skin surgery. Readers of this paper are referred to the BSDS document for further suggestions over the management of the antithrombosed patient, for example the need to weigh up the risk factors and obtain informed consent for a plan agreed with the patient, relevant physicians and surgeons, and the patient's family or advocate.

Isted $\mathrm{et} \mathrm{al}^{25}$ conducted a systematic literature review to determine the risks of haemorrhagic and thromboembolic complications associated with the continuation or cessation of anticoagulant/antiplatelet (AC/AP) therapy in minor cutaneous surgery. They identified 30 studies with data from over 14,000 patients, of which more than 5000 took regular antithrombotic therapy. 
There was no increase in haemorrhagic complications in patients taking aspirin monotherapy, but conflicting evidence regarding warfarin and clopidogrel monotherapy, which showed a small increase in the rate of bleeding complications. However, no increase in wound dehiscence, graft failure, wound infection or cosmetic outcome was seen. Data was sparse in comparing multiple versus single AC/AP regimens and the use of DOACs. Thromboembolic events were rare but carried high morbidity when they did occur in the two papers they reviewed. Isted et al concluded that a case-by-case risk assessment is warranted in all patients but where possible, clinicians should prioritise meticulous haemostasis over cessation of agents. The extrapolation of this review to nail surgery further suggests that continuation of antithrombotic medication should be the norm.

The situation is mirrored in dental surgery where Wahl ${ }^{25,35}$ states: "Although there is now virtually universal consensus among national medical and dental groups and other experts that anticoagulation therapy should not be interrupted for most dental surgery, there are still some arguments made supporting anti-coagulation therapy interruption. An analysis of these arguments shows them to be based on a collection of myths and half-truths rather than on logical scientific conclusions. The time has come to stop anticoagulation therapy interruption for dental procedures".

It seems, therefore, that the fields of dermatology and dental surgery have done the heavy lifting for podiatry to draw upon. As the authors planned this article it was envisaged than an algorithm might be required to guide practice, but having reviewed the associated literature, the situation is somewhat clearer cut for nail surgery. An update for the profession is put forward, and it's about bleeding time. However, in podiatry's defence, the continued heterogeneity of patient management strategies by medics has been highlighted in the literature ${ }^{36}$, exacerbated by the expansion in the range of available antithrombotic drugs ${ }^{25}$.

\section{Conclusion}

Little podiatry-specific evidence was available to guide management of the antithrombosed patient requiring nail surgery. The two papers highlighted in table 2 give appropriate advice and the conclusion of these authors coincides with those put forward. It is hoped that this paper provides greater clarity drawing on work form the associated dermatological literature, where more extensive and aggressive surgical techniques are applied.

Consider each patient on a case-by case basis; take clinical responsibility for decision making but enlist specialist advice where and when necessary. It almost goes without saying - but not quite evaluate, communicate, and document all aspects of the process let there be a later challenge to your clinical judgement. In general - even for the patient on combination therapy - nail surgery can proceed without cessation of antithrombotic medication. This holds true even where resection of hypergranulation tissue is required ${ }^{37}$. Should the clinician have confidence over the patient's INR for example though access to shared computer records - the authors see no absolute requirement to require an opinion from the attending consultant or GP if the patient is on a standard monotherapy (see table 3). That said, patients can be poor historians and courtesy communication to appropriate physicians prior to nail surgery seems prudent. More research in this specific area would be beneficial.

It is common to read on social media platforms that UK podiatrists are 'the experts in nail surgery. This can be challenged both in terms of (not) medically managing our patients, or in only applying a limited range of nail surgery techniques. For the first point, the focus of this article has been one aspect of medical management: patients taking antithrombotics, written for the benefit of UK podiatrists. There is a need for similar research and enquiry to be undertaken for nail surgery on patients who are pregnant/breastfeeding, those with vascular disease, diabetes mellitus, rheumatoid arthritis, or acute infection, and we challenge others to pick up this mantle. Perhaps with time, UK podiatrists will mirror the medical management demonstrated by our American cousins, for example being the clinician that requests an up-to-date INR reading prior to nail surgery. For the latter point, while skilled in the phenol-alcohol technique, a look at the wider dermatology 
literature by authors such as Haneke and Richert will highlight a range of other techniques not performed by UK colleagues. We highly recommend their work.

A final thought that we that hope will bring practitioners comfort when considering surgery on the antithrombosed patient: all patients stop bleeding eventually!

\section{Author information}

1. Department of Podiatric Surgery

Northamptonshire Healthcare Foundation NHS Trust

Danetre Hospital. Daventry. Northamptonshire. NN11 4DY. UK

2. Private Practice

BMI Three Shires and Ramsay Woodlands Hospitals, Northamptonshire. UK

3. Private Practice

J Price Ltd (T/A Footwork Podiatry)

64 The Paddocks, Upper Church Village, Pontypridd. CF38 1TL. UK

Corresponding author: INR (author initials, not the blood assay)

ianreilly@nhs.net

(D) https://orcid.org/0000-0002-2786-5739

https://www.researchgate.net/profile/Ian-Reilly

\section{Declaration}

Northamptonshire Healthcare Foundation NHS Trust does not require ethical approval for reporting clinical guidelines. The authors confirm that they adhered to virtue- and principle-based ethics when producing this work.

INR conceived and wrote the first draft of this document. Both authors approved the final version. The authors confirm that they have no competing interests. This research did not receive any grant from funding agencies in the public, commercial, or not-for-profit sectors. Consent for publication was given by all patients.

This preprint is being submitted to a UK podiatry journal and may be adapted or amended following peer review. 


\section{References}

1. Haneke E. Nail surgery. Clinics in Dermatology. 2013; 31: 516-525.

2. Eekhof JAH, van Wijk B, Neven AK, et al. Interventions for ingrowing toenails. Cochrane Database of Systematic Reviews. 2012(4).

3. Heifetz CJ. Ingrown toenail. A clinical study. The AmericanJournal of Surgery 1937; 38: 298315.

4. Reilly I. Toenail surgery. In: Botting J, Schofield JK (eds) Brown's Skin and Minor Surgery: a text and color atlas. CRC Press. 2014, pp. 289-295.

5. Reilly I. Toenail problems that may require surgery. In: Botting J, Schofield JK (eds) Brown's Skin and Minor Surgery: a text and color atlas. CRC Press. 2014, pp. 170-177.

6. LacoJE. Nail Surgery. In: Hetherington V (ed) Hallux Valgus and Forefoot Surgery. Churchill Livingstone. 1994, pp. 481-496.

7. Reilly I. The Fowler total nail avulsion procedure: a case study. J British Dermatological Nursing Group. 2020; 19: 33-35.

8. Rounding C, Hulm S. Surgical treatments for ingrowing toenails. Foot 2001; 11: 166-182.

9. Haneke E. Controversies in the treatment of ingrown nails. Dermatology Research and Practice. 2012; 1-12.

10. DeLauro NM, DeLauro TM. Onychocryptosis. Clinics in Podiatric Medicine and Surgery. 2004; 21: 617-630.

11. Heidelbaugh JJ, Lee H. Management of the Ingrown Toenail. American Family Physician. 2009; 79: 303-308.

12. Winograd AM. A modification in the technic of operation for ingrown toe-nail. Journal of the American Medical Association. 1929; 92: 229-230.

13. Zadik FR. Obliteration of the nail bed of the great toe without shortening the terminal phalanx. The Journal of Bone and Joint Surgery (Br) 1950; 32: 66-67.

14. Hill A. Personal Communication. 2021.

15. Jones A-M, Pestridge V, Jones L, et al. Nail Surgery Guidance. 2019.

16. Chan NC, Weitz JI. Antithrombotic agents. New directions in antithrombotic therapy. Circulation Research. 2019; 124: 426-436.

17. Brown DG, Wilkerson EC, Love WE. A review of traditional and novel oral anticoagulant and antiplatelet therapy for dermatologists and dermatologic surgeons. Journal of the American Academy of Dermatology. 2015; 72: 524-534.

18. Amici J-M. Don't stop antithrombotics for cutaneous surgery: just do it now! British Journal of Dermatology. 2015; 172: 555-556.

19. Jacobs A. Current insights on perioperative management of anticoagulation therapy. Podiatry Today, https:/www.podiatrytoday.com/blogged/current-insights-perioperative-management-anticoagulation-therapy. 2014 (accessed May 15, 2021).

20. Henley J, Brewer JD. Newer hemostatic agents used in the practice of dermatologic surgery. Dermatology Research and Practice. 2013; 2013: 1-15.

21. Palamaras I, Semkova K. Perioperative management of and recommendations for antithrombotic medications in dermatological surgery. British Journal of Dermatology. 2015; 172: 597-605.

22. Richert B. General considerations. In: Richert B, di Chiacchio N, Haneke E (eds) Nail Surgery. Informa Healthcare. 2011, pp. 16-23.

23. Highland Podiatry Dept. Podiatric management of the nail surgery patient on Vitamin K antagonist oral anticoagulant medicines (VKA-OAM) in primary care. NHS Scotland. 2009.

24. Gohil K. Nail Surgery Guidelines. The College of Podiatry. 2019.

25. Isted A, Cooper L, Colville RJ. Bleeding on the cutting edge: A systematic review of anticoagulant and antiplatelet continuation in minor cutaneous surgery. Journal of Plastic, Reconstructive and Aesthetic Surgery. 2018; 71: 455-467. 
26. Smith TF, Zada LS. Continuous coumadin coagulation: Myth versus reality. Podiatry Institute Update. http://www.podiatrvinstitute.com/pdfs/Update 2006/2006 46.pdf. 2006; 273-276. (accessed May 15, 2021).

27. Sylaidis P, Logan A. Digital blocks with adrenaline: An old dogma refuted. Journal of Hand Surgery (British and European Volume). 1998; 23: 17-19.

28. Prabhakar H, Rath S, Kalaivani M, et al. Adrenaline with lidocaine for digital nerve blocks. Cochrane Database of Systematic Reviews. 2015(3).

29. Bordeaux JS, Martires KJ, Goldberg D, et al. Prospective evaluation of dermatologic surgery complications including patients on multiple antiplatelet and anticoagulant medications. Journal of the American Academy of Dermatology. 2011; 65: 576-583.

30. Bray A, Clarke A. BSDS guidance on antithrombotics and skin surgery. BSDS Executive Committee. 2016; 615-618.

31. Dixon AJ, Dixon MP, Dixon JB. Bleeding complications in skin cancer surgery are associated with warfarin but not aspirin therapy. British Journal of Surgery. 2007; 94: 1356-1360.

32. Callahan S, Goldsberry A, Kim G, et al. The management of antithrombotic medication in skin surgery. Dermatologic Surgery. 2012; 38: 1417-1426.

33. Iyengar S, Yeager DG, Cohen JL, et al. Update and review of bleeding considerations in dermatologic surgery: Anticoagulants and antiplatelets. Dermatologic Surgery. 2020; 46: 192201.

34. Blasdale C, Lawrence CM. Perioperative international normalized ratio level is a poor predictor of postoperative bleeding complications in dermatological surgery patients taking warfarin. British Journal of Dermatology. 2008; 158: 522-526.

35. Wahl MJ. The mythology of anticoagulation therapy interruption for dental surgery. Journal of the American Dental Association. 2018; 149: e1-e10.

36. Khadim MF, Bell PR, Rashid A, et al. A postal survey of UK practice on discontinuation of anticoagulant/antithrombotics therapy before minor cutaneous surgery of the head and neck. Journal of Plastic, Reconstructive \& Aesthetic Surgery. 2011; 64: e213-e215.

37. Reilly I, Burt N. Periungual soft tissue resection. The Podiatrist. 2021; 24: 44-48. 